\title{
THE FEASIBILITY ANALYSIS OF BOEING 737-500 OPERATION AT NORTH ACEH MALIKUSSALEH AIRPORT
}

\author{
Aldrian Nasaifal R \\ Teknik Dirgantara - Institut Teknologi Dirgantara Adisutjipto \\ aldnr26@gmail.com
}

\begin{abstract}
The large number of Acehnese people who are outside Aceh with various needs, such as doing business, working or studying. The optimal transportation to use to the destination quickly in a short time, namely air transportation. North Aceh Malikussaleh Airport is the second busiest airport in Aceh Province.The analysis in this study used PKP-PK analysis, analysis of the feasibility of Boeing 737-500 aircraft using the FPPM method, and analysis of the load capacity of Boeing 737-500 aircraft.From the calculation results, the Boeing 737-500 aircraft is not suitable to be flown at the Malikussaleh Airport in North Aceh due to the limitations of the PKP-PK category level and the strength of the Malikussleh Airport runway. Therefore, North Aceh Malikussaleh Airport must be upgraded.
\end{abstract}

Keywords: FPPM,Take-Off Weight, Allowable Load

1. Pendahuluan

Provinsi Aceh dengan luas daerah sebesar $57.956 \mathrm{~km} 2$ dengan 331 pulau memiliki potensi pariwisata yang potensial untuk dikembangkan. ${ }^{[1][2]}$ Beberapa objek wisata itu diantara adalah waduk Jeulikat, pantai Lampu'uk. Banyaknya wisatawan yang mengunjungi provinsi Aceh berasal dari luar provinsi Aceh seperti Jakarta, Yogyakarta, Bandung, Padang dan Riau.Masyarakat aceh banyak yang berada di luar daerah seperti Jakarta, karena Jakarta mempunyai banyak tempat wisata selain itu juga Jakarta merupakan pusat bisnis dikarenakan padatnya penduduk disana tidak menutup kemungkinan juga bahwa masyarakat Aceh menuju ke Yogyakarta yang dimana banyak mahasiswa- mahasiswa dari aceh hendak menempuh pendidikan disana. Tidak hanya menempuh Pendidikan di Yogyakarta, masyarakat aceh juga bekerja guna memenuhi kebutuhan hidupnya. Potensi meningkatnya kebutuhan transportasi di Aceh itu sangat tinggi. Transportasi yang sangat optimal untuk digunakan guna mengantarkan masyarakat ke tempat tujuan dengan cepat dalam waktu yang singkat yaitu transportasi udara. [3][4]

Transportasi udara juga merupakan transportasi yang aman karena minimnya terjadi kecelakaan di dunia. Provinsi aceh yang berkembang pesawat dengan jumlah animo pergerakan penumpang keluar dan masuk aceh yang semakin banyak. Menurut data BPS tahun 2016-2018, pergerakan penumpang di Aceh semakin meningkat. Terdapat beberapa Bandara yang berada di Aceh seperti Bandar Udara Sultan Iskandar Muda, Bandara Rembele, Bandara Cut Nyak Dhien, Bandara Malikussaleh dan Bandara Maimun Saleh.

Bandara-bandara di Aceh perlu ditingkatkan dengan adanya penumpang yang semakin meningkat pada setiap tahunnya, salah satunya di Bandar Udara Malikussaleh Aceh Utara. Bandar Udara Malikussaleh berada di Kabupaten Aceh Utara, Aceh. Bandara ini tidak hanya melayani kebutuhan transportasi udara masyarakat Aceh Utara dan Lhokseumawe saja, tetapi juga masyarakat Bireuen bahkan Kabupaten Aceh Tengah dan Bener Meriah. Bandara Malikussaleh ini juga merupakan titik kedatangan dan keberangkatan pergerakan penumpang Aceh.Pada tahun 2019, Bandar Udara Malikussaleh merupakan bandara tersibuk kedua dalam pelayanan penerbangan komersil di Aceh setelah Bandar Udara Sultan Iskandar Muda, Banda Aceh. 
Penerbangan di Bandar Udara Malikussaleh ini mencapai 10 kali dalam seminggu. Menurut data BPS tahun 2016-2018, Bandar Udara Malikussaleh ini selalu meningkat pada tiap tahunnya sebesar 5\% sehingga Bandar Udara Malikussaleh ini perlu ditingkatkan. .[5][6] Bandar Udara Malikussaleh saat ini hanya mengoperasikan pesawat ATR-72. Seiring berkembangnya waktu diperlukan peningkatan pesawat Boeing 737-500 agar memudahkan masyarakat Aceh untuk terbang ke lokasi yang lebih jauh dengan nyaman dan aman. Pesawat Boeing 737-500 dapat mengangkut penumpang lebih banyak daripada pesawat ATR-72 sehingga dapat meningkatkan efesiensi waktu dan jumlah penumpang yang dapat diangkut. Lepas landas atau lebih dikenal dengan

Takeoff adalah tahap penerbangan di mana suatu pesawat terbang pada suatu transisi dari berjalan di landasan taksi untuk terbang di udara, pada umumnya diatas suatu landasan pacu. Untuk balon udara, helikopter dan beberapa pesawat terbang dengan sayap khusus (seperti pesawat terbang Harrier), tidak memerlukan landasan pacu. Lepas landas adalah kebalikan dari mendarat..$^{[7][8]}$ Kecepatan diperlukan dalam Lepas landas sangat bervariasi yaitu menurut faktor seperti kepadatan udara, pesawat terbang berat bruto, dan pesawat terbang bentuk wujud ( posisi flap dan/atau slat bisa diterapkan). Kepadatan udara, pada gilirannya, dimakan karat oleh faktor seperti temperatur udara dan tingginya bidang. Hubungan ini antara temperatur, ketinggian, dan kepadatan udara dapat dinyatakan sebagai ketinggian kepadatan, atau ketinggian di dalam Atmospir Standard Internasional yang dimana kepadatan akan sepadan dengan kepadatan udara yang nyata.

Pesawat udara dirancang untuk beroperasi kecepatan tinggi (termasuk pesawat terbang komersil) mempunyai kesulitan tinggi saat mengangkat di kecepatan rendah yang ditemui selama lepas landas. Hal ini yang kemudian dicoba dengan dengan memakai peralatan highlift, meliputi slats dan pada umumnya flap, yang mana dapat meningkatkan permukaan sayap, dan menjadikan lebih efektif pada kecepatan rendah, sehingga dapat lebih terangkat. Posisi sayap lebih melebar sebelum takeoff, dan menarik kembali setelah pesawat mengudara. Sayap dapat juga menyebar pada lain waktu, seperti saat sebelum mendarat. ${ }^{[9][10] ~[11] ~}$

\section{Metode Penelitian}

Objek Penelitian ini yaitu Pesawat Boeing 737-500 sedangkan subjek pada penelitian ini yaitu Bandar Udara malikussaleh. Skripsi ini membahas tentang apakah pesawat Boeing 737500 ini dapat dioperasikan di Bandar Udara Malikussaleh Aceh Utara.

Metode penelitian yang digunakan yaitu sebagai berikut.

- Analisa Perkembangan Bandar Udara

Analisa ini menggunakan forecast linier untuk 10 tahun kedepan, sehingga dapat memprediksikan penumpang untuk 10 tahun kedepan. Analisa ini menggunakan data Badan Pusat Statistika tahun 2014 - 2018 penumpang yang berangkat dari Bandar Udara Malikussaleh.

- Analisa Kelayakan Pesawat Boeing 737-500

Analisa ini diperoleh dari data-data yang didapatkan dari field research seperti datadata Bandar Udara Malikussaleh, serta keadaan lingkungan disekitar Bandar Udara Malikussaleh. Analisa ini menggunakan FPPM (Flight Planning and Performance Manual) Pesawat Boeing 737-500.

- Analisa Fasilitas Bandar Udara

Pada setiap Bandar Udara memiliki fasilitas yang berbeda-beda, sehingga tidak semua bandara dapat mengoperasikan pesawat yang sama pula. Maka dari itu diperlukan analisa fasilitas Bandar Udara Malikussaleh Aceh Utara.

- Analisa Kapasitas Muat Pesawat Boeing 737-500

Analisa Kapasitas Muat Pesawat Boeing 737-500 ini menggunakan rute penerbangan dari Bandar Udara malikussaleh Aceh Utara ke 3 rute yang berbeda yaitu Bandar 
Udara Internasional Kualanamu Medan, Bandar Udara Internasional Soekarno-Hatta Jakarta dan Bandar Udara Internasional Yogyakarta.

\section{Hasil dan Analisis}

Forecasting linier yang digunakan adalah forecasting dengan menggunakan nilai tengah sebagai dasar, yang dimana pada tahun 2016 sebagai titik tengahnya sehingga nilai $\mathrm{X}$ di tahun 2016 yaitu 0 . Untuk tahun berikutnya nilai $X$ dimulai angka 1 dan seterusnya, sebaliknya di tahun sebelumnya nilai X-nya dimulai dari -1 dan seterusnya. Banyaknya data yang digunakan adalah 5. Selanjutnya dilakukan perhitungan dari data yang telah didapatkan seperti pada table berikut ini.

Tabel 1. Menghitung Forecasting Linier

\begin{tabular}{|c|c|c|c|c|}
\hline Tahun & Penumpang $(\mathrm{Y})$ & $(\mathrm{X})$ & $(\mathrm{XY})$ & $\mathrm{X}^{\wedge} 2$ \\
\hline \hline 2014 & 5.363 & -2 & -10.726 & 4 \\
\hline 2015 & 14.744 & -1 & -14.744 & 1 \\
\hline 2016 & 23.838 & 0 & 0 & 0 \\
\hline 2017 & 26.073 & 1 & 26.073 & 1 \\
\hline 2018 & 23.999 & 2 & 47.998 & 4 \\
\hline \hline Jumlah & 94.017 & 0 & 48.601 & 10 \\
\hline
\end{tabular}

Nilai " $\alpha$ " dan " $\beta$ " dicari dengan menggunakan formula sebagai berikut.

$\alpha=\frac{\Sigma Y}{n} \quad \operatorname{dan} \beta=\frac{\Sigma X Y}{X^{2}}$

$\alpha=\frac{\Sigma Y}{n}=\frac{94.017}{5}=18.803$

$\beta=\frac{\Sigma X Y}{X^{2}}=\frac{48601}{10}=4.860$

Sehingga didapatkan persamaan linier sebagai berikut.

$Y=\alpha+\beta \mathrm{x}$

$$
Y=18.803+4.860 x
$$

Tabel 2. Ramalan Jumlah Penumpang dalam 10 Tahun Kedepan

\begin{tabular}{|c|c|}
\hline Tahun & $\begin{array}{c}\text { Ramalan Jumlah Penumpang } \\
\text { (orang) }\end{array}$ \\
\hline 2021 & 43.103 \\
\hline 2022 & 47.964 \\
\hline 2023 & 52.824 \\
\hline 2024 & 57.684 \\
\hline 2025 & 62.544 \\
\hline 2026 & 67.404 \\
\hline 2027 & 72.264 \\
\hline 2028 & 77.124 \\
\hline 2029 & 81.984 \\
\hline 2030 & 86.844 \\
\hline 2031 & 91.704 \\
\hline
\end{tabular}


Dari data diatas dapat disimpulkan bahwa pada tiap tahunnya terdapat kenaikan penumpang sebesar 1\% hingga 5\%. Menurut forecasting yang telah dihitung, pada tahun 2031 penumpang melonjak dengan pesat yaitu 91.704 penumpang pertahun, atau 7.642 penumpang perbulan atau rata-rata 254 penumpang perharinya sehingga pesawat terbang sekelas ATR-72 tidak efektif dioperasikan, maka dari itu dibutuhkan pesawat yang lebih besar seperti Pesawat Boeing 737-500 guna kelancaran operasi penerbangan di Bandara Malikussaleh.Keunggulan menggunakan Pesawat Boeing 737-500 juga dapat menjelajah hingga jarak $2950 \mathrm{~nm}$ sehingga mobilisasi pergerakan penumpang akan lebih jauh lagi seperti penumpang dari Bandara Malikussaleh menuju Bandara Soekarno Hatta, Jakarta, Sultan Aji Muhammad Sulaiman, Balikpapan dan Radin Inten II, Lampung. Perhitungan daya muat terlebih dahulu harus diketahui beberepa unsur pendukung penghitungan daya muat, yaitu: Mendapatkan data berat Pesawat dalam Dry Operating Weight (DOW). Dari data yang didapatkan pada hasil observasi di beberapa maskapai penerbanagn diketahui berat pesawat dalam DOW adalah seperti terlihat pada table berikut ini.

Tabel 3. Perhitungan Dry Operating Weight

\begin{tabular}{|c|c|}
\hline $\begin{array}{c}\text { Aircraft } \\
\text { Registration }\end{array}$ & $\begin{array}{c}\text { DOW } \\
\text { Kg }\end{array}$ \\
\hline PK - GKB & 31.900 \\
\hline PK - CLE & 32.000 \\
\hline PK - LKN & 31.700 \\
\hline PK - LNN & 31.700 \\
\hline PK - LAM & 31.700 \\
\hline Rata-Rata & 31.800 \\
\hline
\end{tabular}

Menghitung kapasitas muat penerbangan

Menghitung kapasitas muat dengan basic information berupa :

MZFW : $46.720 \mathrm{Kg}$

MLDW : $49.895 \mathrm{Kg}$

DOW : $31.800 \mathrm{Kg}$

1. Penerbangan WIMA - WIMM

Blockfuel : $7.500 \mathrm{Kg}$

Trip Fuel : $1.413 \mathrm{Kg}$

Taxifuel : $200 \mathrm{Kg}$

Operating Weight = DOW + Take-offfuel

Operating Weight $=\mathrm{DOW}+($ Block Fuel - Taxi Fuel $)$

Operating Weight $=31.800+(7.500-200)$

Operating Weight $=31.800+7.300$

Operating Weight $=39.100 \mathrm{Kg}$

a. Kondisi KWP

Allowed weight for take-off $=54.700 \mathrm{~kg}$

Allowed weight for zero fuel weight

$=\mathrm{MZFW}+$ Take-Off Fuel

$=\mathrm{MZFW}+($ Block Fuel - Taxi Fuel $)$

$=46.720+(7.500-200)$

$=54.020 \mathrm{Kg}$ 
Allowed weight for landing

$=$ MLDW + Trip Fuel

$=49.895+1.413$

$=51.308 \mathrm{Kg}$

Allowed weight for the flight adalah nilai terendah dari ketiga diatas yaitu $51.308 \mathrm{Kg}$.

Menghitung kapasitas muat penerbangan yaitu sebagai berikut.

$=$ Lowest allowed load - Operating weight

$=51.308-39.100$

b. Kondisi KWS

$$
=12.208 \mathrm{Kg}
$$

Allowed weight for take-off $=54.000 \mathrm{~kg}$

Allowed weight for zero fuel weight

$=\mathrm{MZFW}+$ Take-Off Fuel

$=\mathrm{MZFW}+($ Block Fuel - Taxi Fuel $)$

$=46.720+(8.500-200)$

$=55.020 \mathrm{Kg}$

Allowed weight for landing

= MLDW + Trip Fuel

$=49.895+1.413$

$=51.308 \mathrm{Kg}$

Allowed weight for the flight adalah nilai terendah dari ketiga diatas yaitu $51.308 \mathrm{Kg}$.

Menghitung kapasitas muat penerbangan yaitu sebagai berikut.

$=$ Lowest allowed load - Operating weight

$=51.308-39.100$

$=12.208 \mathrm{Kg}$

2. Penerbangan WIMA - WIII

Blockfuel : $13.000 \mathrm{Kg}$

Trip Fuel : $8.303 \mathrm{Kg}$

Taxifuel : $200 \mathrm{Kg}$

Operating Weight $=\mathrm{DOW}+$ Take-offfuel

Operating Weight $=\mathrm{DOW}+($ Block Fuel - Taxi Fuel $)$

Operating Weight $=31.800+(13.000-200)$

Operating Weight $=31.800+12.800$

Operating Weight $=44.600 \mathrm{Kg}$

a. Kondisi KWP

Allowed weight for take-off $=54.700 \mathrm{~kg}$

Allowed weight for zero fuel weight

$=\mathrm{MZFW}+$ Take-Off Fuel

$=\mathrm{MZFW}+($ Block Fuel - Taxi Fuel $)$

$=46.720+(13.000-200)$

$=59.520 \mathrm{Kg}$

Allowed weight for landing

$=$ MLDW + Trip Fuel

$=49.895+8.303$

$=58.198 \mathrm{Kg}$

Allowed weight for the flight adalah nilai terendah dari ketiga diatas yaitu $54.700 \mathrm{Kg}$. 
Menghitung kapasitas muat penerbangan yaitu sebagai berikut.

$=$ Lowest allowed load-Operating weight

$=54.700-44.600$

$=10.100 \mathrm{Kg}$

b. Kondisi KWS

Allowed weight for take-off $=54.000 \mathrm{~kg}$

Allowed weight for zero fuel weight

$=\mathrm{MZFW}+$ Take-Off Fuel

$=\mathrm{MZFW}+($ Block Fuel - Taxi Fuel $)$

$=46.720+(13.000-200)$

$=59.520 \mathrm{Kg}$

Allowed weight for landing

$=$ MLDW + Trip Fuel

$=49.895+8.303$

$=58.198 \mathrm{Kg}$

Allowed weight for the flight adalah nilai terendah dari ketiga diatas yaitu $54.700 \mathrm{Kg}$.

Menghitung kapasitas muat penerbangan yaitu sebagai berikut.

$=$ Lowest allowed load - Operating weight

$=54.000-44.600$

$=9.400 \mathrm{Kg}$

3. Penerbangan WIMA - WAHI

Blockfuel : $13.500 \mathrm{Kg}$

Trip Fuel : $10.291 \mathrm{Kg}$

Taxifuel : $200 \mathrm{Kg}$

Operating Weight $=\mathrm{DOW}+$ Take-offfuel

Operating Weight $=\mathrm{DOW}+($ Block Fuel - Taxi Fuel $)$

Operating Weight $=31.800+(13.500-200)$

Operating Weight $=31.800+13.300$

Operating Weight $=45.100 \mathrm{Kg}$

a. Kondisi KWP

Allowed weight for take-off $=54.700 \mathrm{~kg}$

Allowed weight for zero fuel weight

$=$ MZFW + Take-Off Fuel

$=\mathrm{MZFW}+($ Block Fuel - Taxi Fuel $)$

$=46.720+(13.500-200)$

$=60.020 \mathrm{Kg}$

Allowed weight for landing

$=$ MLDW + Trip Fuel

$=49.895+10.291$

$=60.186 \mathrm{Kg}$

Allowed weight for the flight adalah nilai terendah dari ketiga diatas yaitu $54.700 \mathrm{Kg}$.

Menghitung kapasitas muat penerbangan yaitu sebagai berikut.

$=$ Lowest allowed load -Operating weight

$=54.700-45.100$

$=9.600 \mathrm{Kg}$

b. Kondisi KWS

Allowed weight for take-off $=54.000 \mathrm{~kg}$

Allowed weight for zero fuel weight 


$$
\begin{aligned}
& =\text { MZFW }+ \text { Take-Off Fuel } \\
& =\mathrm{MZFW}+(\text { Block Fuel }- \text { Taxi Fuel }) \\
& =46.720+(13.500-200) \\
& =60.020 \mathrm{Kg}
\end{aligned}
$$

Allowed weight for landing

$$
\begin{aligned}
& =\text { MLDW + Trip Fuel } \\
& =49.895+10.291
\end{aligned}
$$$$
=60.186 \mathrm{Kg}
$$

Allowed weight for the flight adalah nilai terendah dari ketiga diatas yaitu $54.000 \mathrm{Kg}$.

\begin{tabular}{|c|c|c|c|c|}
\hline \multicolumn{2}{|c|}{ Rute Penerbangan } & Alternate & $\begin{array}{c}\text { Kelompok } \\
\text { Waktu }\end{array}$ & $\begin{array}{l}\text { Kapasitas muat } \\
\mathrm{Kg}\end{array}$ \\
\hline \multirow{2}{*}{$\begin{array}{c}\text { Aceh Utara - } \\
\text { Malikussaleh Airport/ WIMA - }\end{array}$} & \multirow{2}{*}{$\begin{array}{c}\text { Medan } \\
\text { Kualanamo Airport/ WIMM }\end{array}$} & \multirow{2}{*}{$\begin{array}{c}\text { Batam } \\
\text { Hang Nadim Airport / WIDD }\end{array}$} & Waktu Pagi & 12.208 \\
\hline & & & Waktu Siang & 12.208 \\
\hline \multirow{2}{*}{$\begin{array}{c}\text { Aceh Utara - } \\
\text { Malikussaleh Airport/ WIMA - }\end{array}$} & \multirow{2}{*}{$\begin{array}{c}\text { Jakarta } \\
\text { Soekarno-Hatta Airport / WIII } \\
\end{array}$} & \multirow{2}{*}{\begin{tabular}{|c|} 
Palembang \\
Sultan Mahmud Badaruddin II / WIPP \\
\end{tabular}} & Waktu Pagi & 10.100 \\
\hline & & & Waktu Siang & 9.400 \\
\hline \multirow{2}{*}{\multicolumn{2}{|c|}{$\begin{array}{cc}\text { Aceh Utara } & - \\
\text { Malkussaleh Airport/ WIMA - } & \text { Yogyakakarta Airport / WAHI }\end{array}$}} & \multirow{2}{*}{$\begin{array}{c}\text { Surabaya } \\
\text { Juanda Airport/WARR }\end{array}$} & Waktu Pagi & 9.600 \\
\hline & & & Waktu Siang & 8.900 \\
\hline
\end{tabular}

Menghitung kapasitas muat penerbangan yaitu sebagai berikut.

$$
\begin{aligned}
& =\text { Lowest allowed load }- \text { Operating weight } \\
& =54.000-45.100 \\
& =8.900 \mathrm{Kg}
\end{aligned}
$$

Dari Perhitungan diatas di dapatkan kapasitas muat pesawat dari 3 rute dengan kondisi waktu pagi (KWP) dan kelompok waktu siang (KWS) yaitu sebagai berikut.

Tabel 4. Kapasitas Muat Pesawat

Perhitungan Pasengger Pax dan Kargo

Dalam Standart IATA untuk penerbangan domestik, standard passenger pax yaitu $70 \mathrm{Kg}$ (orang dewasa) dan cargo $15 \mathrm{Kg}$. Pesawat Boeing 737-500 hanya dapat menampung penumpang 110 pax passenger, maka dari itu Pesawat Boeing 737-500 dapat memuat yaitu sebagai berikut.

1. Penerbangan WIMA - WIMM (KWP \& KWS)

Formula pax passenger:

$$
\begin{aligned}
& \text { Pax Passenger }=\frac{\text { Kapasitas muat }}{(\text { Passengger }+ \text { Cargo })} \\
& \text { Pax Passenger }=\frac{12.208}{(70+15)} \\
& \text { Pax Passenger }=\frac{12.208}{85} \\
& \text { Pax Passenger }=143,6 \approx 110 \text { Pax (maksimal })
\end{aligned}
$$

Allowed Cargo for flight:

Cargo $=$ Kapasitas muat $-($ Pax Passenger $x 70)$

Cargo $=12.208-(110 \times 70)$

Cargo $=12.208-7.700$

Cargo $=4.508 \mathrm{Kg}$ 
2. Penerbangan WIMA - WIII (KWP)

Formula pax passenger:

Pax Passenger $=\frac{\text { Kapasitas muat }}{(\text { Passengger }+ \text { Cargo })}$

Pax Passenger $=\frac{10.100}{(70+15)}$

Pax Passenger $=\frac{10.100}{85}$

Pax Passenger $=118,8 \approx 110$ Pax (maksimal)

Allowed Cargo for flight:

Cargo $=$ Kapasitas muat $-($ Pax Passenger $x 70)$

Cargo $=10.100-(110 \times 70)$

Cargo $=10.100-7.700$

Cargo $=2.400 \mathrm{Kg}$

3. Penerbangan WIMA - WIII (KWS)

Formula pax passenger:

Pax Passenger $=\frac{\text { Kapasitas muat }}{(\text { Passengger }+ \text { Cargo })}$

Pax Passenger $=\frac{9.400}{(70+15)}$

Pax Passenger $=\frac{9.400}{85}$

Pax Passenger $=110,5 \approx 110$ Pax

Allowed Cargo for flight:

Cargo $=$ Kapasitas muat $-($ Pax Passenger $x 70)$

Cargo $=9.400-(110 \times 70)$

Cargo $=9.400-7.700$

Cargo $=1.700 \mathrm{Kg}$

4. Penerbangan WIMA - WAHI (KWP)

Formula pax passenger:

Pax Passenger $=\frac{\text { Kapasitas muat }}{(\text { Passengger }+ \text { Cargo })}$

Pax Passenger $=\frac{9.600}{(70+15)}$

Pax Passenger $=\frac{9.600}{85}$

Pax Passenger $=112,9 \approx 110$ Pax (maksimal)

Allowed Cargo for flight:

Cargo $=$ Kapasitas muat $-($ Pax Passenger $x 70)$

Cargo $=9.600-(110 \times 70)$

Cargo $=9.600-7.700$

Cargo $=1.900 \mathrm{Kg}$ 
5. Penerbangan WIMA - WAHI (KWS)

Formula pax passenger:

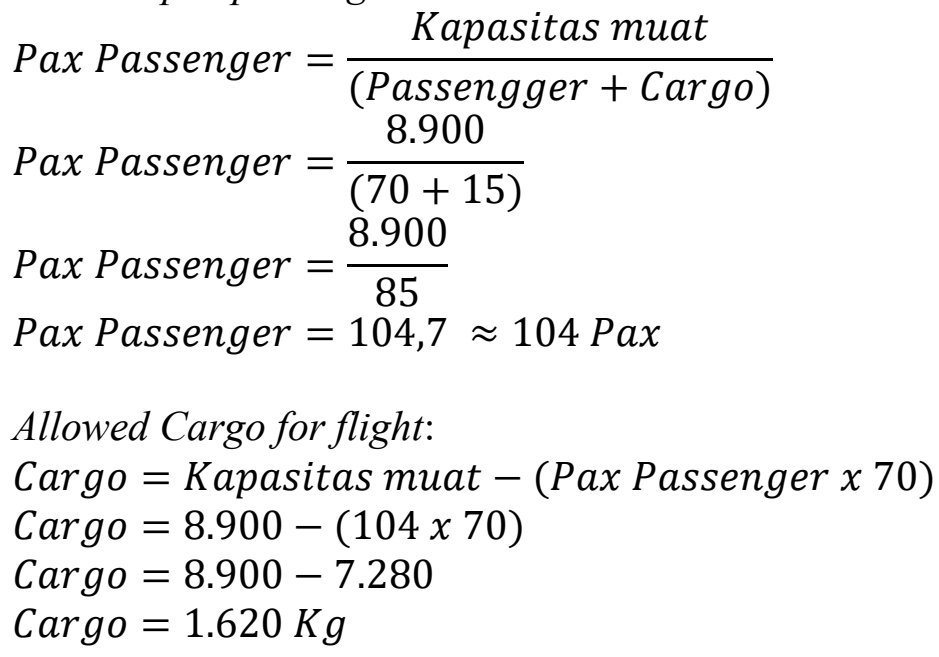

Dari Perhitungan diatas dapat disimpulkan bahwa Passenger pax dan cargo pesawat dari 3 rute dengan kondisi waktu pagi (KWP) dan kelompok waktu siang (KWS) yaitu sebagai berikut.

Tabel 5. Passenger Pax dan Cargo

\begin{tabular}{|c|c|c|c|}
\hline Rute Penerbangan & \multirow{2}{*}{ Alternate } & $\begin{array}{c}\text { Kelompok } \\
\text { Waktu }\end{array}$ & \multicolumn{2}{|c|}{ Kapasitas muat } \\
\hline \multirow{2}{*}{ Malikussaleh - Kualanamu } & \multirow{2}{*}{ Batam } & Waktu Pagi & $12.208 \mathrm{~kg}(110 \mathrm{pax}+4.508 \mathrm{~kg} \mathrm{Cgo})$ \\
\cline { 3 - 5 } & & Waktu Siang & $12.208 \mathrm{~kg}(110 \mathrm{pax}+4.508 \mathrm{~kg} \mathrm{Cgo})$ \\
\hline \multirow{2}{*}{ Malikussaleh - Soetta } & \multirow{2}{*}{ Palembang } & Waktu Pagi & $10.100 \mathrm{~kg}(110 \mathrm{pax}+2.400 \mathrm{~kg} \mathrm{Cgo})$ \\
\cline { 3 - 5 } Malikussaleh - Yogyakarta & \multirow{2}{*}{ Surabaya } & Waktu Siang & $9.400 \mathrm{~kg}(110 \mathrm{pax}+1.700 \mathrm{~kg}$ Cgo $)$ \\
\cline { 3 - 5 } & & Waktu Pagi & $9.600 \mathrm{~kg}(110 \mathrm{pax}+1.900 \mathrm{~kg}$ Cgo $)$ \\
\hline
\end{tabular}

\section{Kesimpulan}

Dengan kondisi Bandar Udara Malikussaleh saat ini, Pesawat Boeing 737-500 tidak dapat dioperasikan di Bandar Udara Malikussaleh Aceh Utara dikarenakan kekuatan landasannya sebesar PCN 25/F/C/Y/T dan kesiapan \& kelengkapan PKP-PK tingkat kategori 5. Pesawat Boeing 737-500 dapat beroperasi di Bandar Udara Malikussaleh jika dengan kondisi minimum sebagai berikut. Bandar Udara Malikussaleh meningkatkan kekuatan landasan dari PCN 25/F/C/Y/T menjadi PCN 33/F/C/Y/T. Bandar Udara Malikussaleh meningkatkan kemampuan PKP-PK dari tingkat kategori 5 menjadi tingkat kategori 6. Berdasarkan Peraturan Direktorat Jenderal Perhubungan Udara No. KP. 420 Tahun 2011, Kategori 6 PKP-PK memiliki kendaraan utama 2 Foam Tender IV dan 1 Back up Foam Tender IV. Foam Tender IV memiliki kapasitas tangka air 4.000 liter, tangka foam konsetrat 500 liter, kapasitas tangki tepung kimia (dry chemical powder) $250 \mathrm{Kg}$, kapasitas pompa minimum 2.500 liter per menit; dilengkapi dengan handlines, nozzle dibawah dan didepan kendaraan. Kendaraan Pendukung yang dibutuhkan pada kategori 6 PKP-PK yaitu 1 Comando Car, 1 Nurse Tender dan 2 Ambulance. Secara personil, PKP-PK tingkat kategori 6 memiliki 24 personil per-shift yaitu 5 senior, 6 
junior, 10 basic dan 3 teknik pemeliharaan. Jika ketentuan point ke-2 terpenuhi, maka kapasitas muat Pesawat Boeing 737-500 dengan 3 rute penerbangan yaitu:

a. Rute penerbangan Bandar Udara Malikussaleh ke Bandar Udara Internasional Kualanamu Medan, dalam kondisi kelompok waktu pagi maupun kelompok waktu siang pesawat Boeing 737-500 dapat mengangkut kapasitas muat sebesar $11.208 \mathrm{Kg}$. Kapasitas muat 11.208 dapat mengangkut 131 penumpang dengan kargo $2.038 \mathrm{Kg}$.

b. Rute penerbangan Bandar Udara Malikussaleh ke Bandar Udara Internasional SoekarnoHatta Jakarta, dalam kondisi kelompok waktu pagi dapat mengangkut kapasitas muat sebesar $10.100 \mathrm{Kg}$ (118 penumpang \& $1.840 \mathrm{Kg})$, sedangkan dalam kondisi kelompok waktu siang dapat mengangkut kapasitas muat sebesar $9.400 \mathrm{Kg}$ (110 penumpang \& 1.700 $\mathrm{Kg})$.

c. Rute penerbangan Bandar Udara Malikussaleh ke Bandar Udara Internasional SoekarnoHatta Jakarta, dalam kondisi kelompok waktu pagi dapat mengangkut kapasitas muat sebesar $9.600 \mathrm{Kg}$ (112 penumpang \& $1.760 \mathrm{Kg})$, sedangkan dalam kondisi kelompok waktu siang dapat mengangkut kapasitas muat sebesar $8.900 \mathrm{Kg}$ (104 penumpang \& 1.620 $\mathrm{Kg})$.

\section{DAFTAR PUSTAKA}

[1] Hasna, Ismawati. 2019. "Analisis Perbandingan Performa Take Off Boeing 737 -800NG dan Boeing 737-900ER dengan Data Struktur Pesawat Saat Beroperasi di Bandar Udara Internasional Jenderal Ahmad Yani Semarang"

[2] U1 Husna, Annisa. 2017. "Analisis Perhitungan Biaya Operasional untuk Pemilihan Tipe Pesawat Terbang Rute Yogyakarta-Padang"

[3] Fajri, Khairul. 2019. "Analisis Drift Down Pesawat ATR72-500 Rute Lampung-Padang Pada Kondisi One Engine Inoperative"

[4] FAA. 2000. Flight Planning and Performance Manual Boeing 737-500. CFM56-3_20K

[5] Budiman, Arifal Hidayat ST, MT. dan Bambang Edison, S.pd, MT. 2020. Perencanaan Landasan Pacu Bandar Udara Tuanku Tambusan Kabupaten Rokan Hulu.

[6] Susanti dan Kusumaningrum, Jennie. 2019. Perencanaan Runway dan Taxiway serta Perbaikan Subgrade pada Bandar Udara Juwata, Tarakan.

[7] ICAO Doc 9157 AN/901. 2006. Aerodrome Design Manual Part 1 Runways. International Civil Aviation Organization.

[8] Pemerintah Indonesia. 2011. Peraturan Direktur Jenderal Perhubungan Udara Nomor: 420 Tahun 2011 Tentang Persyaratan Standar Teknis dan Operasional Peraturan Keselamatan Penerbangan Sipil Bagian 139 (Manual Of Standard CASR Part 139) Volume IV Pelayanan Pertolongan Kecelakaan Penerbangan Dan Pemadam Kebakaran (PKP-PK).

[9] Pemerintah Indonesia. 2015. Peraturan Direktur Jenderal Perhubungan Udara Nomor: 39 Tahun 2015 Tentang Standar Teknis dan Operasi Peraturan Keselamatan Penerbangan Sipil - Bagian 139 (Manual of Standard CASR - Part 139) Volume I Bandar Udara (Aerodromes).

[10] Siregar, Syofian. 2013. Metode Penelitian Kuantitatif. Jakarta: PT Fajar Interpratama Mandiri.

[11] Ghozali, Imam. (2018). Aplikasi Analisis Multivariate Dengan Program IBM SPSS 25. Semarang: Badan Penerbit-UNDIP 